\title{
Fabrication of bioactive polycaprolactone/hydroxyapatite scaffolds with final bilayer nano-/micro-fibrous structures for tissue engineering application
}

\author{
Izabella Rajzer
}

Received: 12 January 2014/ Accepted: 7 May 2014/Published online: 21 May 2014

(c) The Author(s) 2014. This article is published with open access at Springerlink.com

\begin{abstract}
In this study, two techniques, namely electrospinning and needle-punching processes, were used to fabricate bioactive polycaprolactone/hydroxyapatite scaffolds with a final bilayer nano-/micro-fibrous porous structure. A hybrid scaffold was fabricated to combine the beneficial properties of nanofibers and microfibers and to create a three-dimensional porous structure (which is usually very difficult to produce using electrospinning technology only). The first part of this work focused on determining the conditions necessary to fabricate nano- and micro-fibrous components of scaffold layers. A characterization of scaffold components, with respect to their morphology, fiber diameter, pore size, wettability, chemical composition and mechanical properties, was performed. Then, the same process parameters were applied to produce a hybrid bilayer scaffold by electrospinning the nanofibers directly onto the micro-fibrous nonwovens obtained in a traditional mechanical needle-punching process. In the second part, the bioactive character of a hybrid nano-/ micro-fibrous scaffold in simulated body fluid (SBF) was assessed. Spherical calcium phosphate was precipitated onto the nano-/micro-fibrous scaffold surface proving its bioactivity.
\end{abstract}

\section{Introduction}

A number of fabrication technologies have been applied to produce an ideal scaffold for bone tissue engineering [1].

\section{Rajzer $(\bowtie)$}

Division of Materials Engineering, Department of Mechanical Engineering Fundamentals, ATH University of Bielsko-Biala, Willowa 2 Street, 43-309 Bielsko-Biała, Poland

e-mail: irajzer@ath.bielsko.pl
Fiber-based structures represent a wide range of morphological and geometric possibilities that can be tailored for each specific tissue engineering application [2, 3]. Recently, electrospinning of nanofibers has been widely researched and numerous composite nanofibers, containing bioactive molecules, have been prepared to match the requirements for bone tissue scaffolds [4-6]. Current developments include the fabrication of nanofibrous scaffolds which, due to their similarity to the extracellular matrix $(\mathrm{ECM})$, can provide chemical, mechanical and biological signals to respond to the environmental stimuli [7]. Several investigators have developed electrospun scaffolds that combine degradable polymers such as polycaprolactone (PCL) with nano-hydroxyapatite (nHAp) $[8,9]$. Many studies have discovered that a composite of PCL/n-HAp biomaterials generally favors calcium phosphate mineralization followed by an osteogenic differentiation process [10-12]. Several studies have showed that, by introducing a bone-bioactive inorganic component (n-HAp) into the PCL matrix, better interaction and improved cell adhesion with the biological environment can be achieved [13]. It is well known that interconnected pores in tissue engineering scaffolds are essential for cell growth, migration, vascularization, and tissue formation [14]. Electrospinning is a process that can generate a fibrous scaffold with high porosity, interconnected pores, a large surface-area-to-volume ratio and a variable fiber diameter [15]. However, the small pore size of electrospun nanofibrous scaffolds may limit cellular infiltration [16]. Pore size below cellular diameter cannot allow cell migration within the structure [17]. Porosity and thereby cell penetration could be enhanced in scaffolds by using the strategy of creating a 3D nano-/micro-architecture, where nanofibers are combined with microfibers [1822]. Nano-/micro-fibrous scaffolds have an innovative 
structure, inspired by an ECM that combines a nano-network, aimed to promote cell adhesion, with a micro-fiber mesh to generate the 3-D structure [23, 24]. Although micro-fibrous scaffolds are not on the same size scale as ECM components, they could potentially be advantageous because they are composed of larger pores as compared to nano-fibrous scaffolds [25]. Conventional textile technologies, which are simple and nontoxic (such as the needlepunching technique), can generate highly porous, microfibrous nonwovens with interconnected pores suitable for tissue engineering scaffolds [26]. Moreover, modification of fibers using bioactive ceramic particles can lead to the development of new materials for the manufacturing of implants which can establish direct chemical bonds with bone tissue after implantation [27, 28]. A nano-fibrous membrane in a bilayer scaffold can also act as a barrier membrane which serves two functions: it is permeable to nutrients yet, when coupled with a micro-fibrous scaffold, allows for the proliferation of cells on both sides of the barrier while at the same time preventing the unwanted migration of cells across the barrier [29].

This study focused on producing bilayer hybrid nano-/ micro-fibrous composite scaffolds of poly( $\varepsilon$-caprolactone) modified with hydroxyapatite nanoparticles for tissue engineering application. The first part of this work concentrated on determining the conditions necessary to produce nano- and micro-fibrous components of scaffold layers. A characterization of scaffold components with respect to their morphology, fiber diameter, pore size, wettability, chemical composition, and mechanical properties was performed. Then, the same process parameters were applied to produce a hybrid bilayer scaffold by electrospinning nanofibers directly onto the micro-fibrous nonwovens obtained in a traditional mechanical needlepunching process. In the second part, the bioactive character of the hybrid nano-/micro-fibrous scaffold was assessed.

\section{Materials and methods}

Scaffold fabrication

Nano-fibrous scaffolds

In this study, nano-fibrous scaffolds were produced by electrospinning. Poly( $\varepsilon$-caprolactone) from Sigma-Aldrich, with an average molecular weight of $80 \mathrm{kDa}$, was dissolved into equal parts of chloroform and methanol (POCH, Poland) at a concentration of $6 \%(\mathrm{wt} / \mathrm{vol})$. For the composite scaffold, the PCL solution was mixed with $20 \mathrm{wt} \%$ of n-HAp (AGH, Cracow, Poland) [30]. The solutions were loaded into a $10 \mathrm{~mL}$ plastic syringe with a stainless-steel blunt needle (diameter $0.7 \mathrm{~mm}$ ). The needle was connected to a high-voltage power supply which generated a voltage of $30 \mathrm{kV}$. The flow rate of the solution was $1.5 \mathrm{~mL} / \mathrm{h}$. The fibers were collected on a rotary drum (diameter: $60 \mathrm{~mm}$; length: $300 \mathrm{~mm}$; rotation speed: $230 \mathrm{rpm}$; linear velocity: $0.72 \mathrm{~m} / \mathrm{s}$ ) wrapped with a piece of silica-coated paper which was placed at a distance of $15 \mathrm{~cm}$ from the needle tip. The deposition was perform for a duration of $3 \mathrm{~h}$. Two types of electrospun scaffolds were formed: (1) pure PCL (nPCL) and (2) PCL modified with n-HAp (nPCL/n-HAp).

\section{Micro-fibrous scaffolds}

Micro-fibrous scaffolds were produced using a traditional needle-punching process. Before scaffold fabrication, pure PCL and composite PCL/n-HAp fibers were produced using the melt spinning method, with a prototype laboratory spinning machine PROMA (Torun, Poland) as previously described [31]. In order to obtain composite fibers, n-HAp powder (5 wt \%) was premixed into the PCL polymer before melting. This amount of n-HAp powder was chosen based on previous studies in which the higher concentration of nanoparticles resulted in a significant decrease in the mechanical properties of the fibers [32]. The premixing process was applied in order to obtain homogeneously mixed components. In the premixing process, hydroxyapatite powder and polymer granulates were premixed in the mixer and then fed into the extruder. The extruder homogenized them and a masterbatch of PCL/nHAp was produced before the principal process of forming fibers. Fibers were extruded from the melted components at a temperature of $170{ }^{\circ} \mathrm{C}$ and were spun with a take-up velocity of $247 \mathrm{~m} / \mathrm{min}$. The obtained fibers were then carded using a laboratory carding machine and arranged in a 2D sheet with a random fiber orientation. The fibers in the web were then bonded together using a needle-punching process. For both samples, the same amount of needling and needling depth was used. Finally, two types of nonwoven scaffolds were obtained using this method: (1) pure PCL (mPCL) and (2) PCL modified with n-HAp (mPCL/nHAp).

\section{Hybrid nano/micro-fibrous scaffolds}

Hybrid bilayer scaffolds consisting of a top nanofiber layer and a bottom microfiber layer were obtained by electrospinning nPCL or nPCL/n-HAp nanofibers directly onto the micro-fibrous mPCL or mPCL/n-HAp nonwoven scaffolds. The same electrospinning process parameters for nanofibrous scaffold fabrication were applied to produce a hybrid bilayer scaffolds. The nanofibers were collected on a rotary drum wrapped with a mPCL or mPCL/n-HAp nonwovens. 
Two types of hybrid materials were obtained: (1) a nonmodified hybrid scaffold (H-PCL) and (2) a n-HAp modified hybrid scaffold (H-PCL/n-HAp).

\section{Scaffold characterization}

In order to determine the diameter and morphology of the nano- and micro-fibrous materials, scaffold samples were covered by a sputtered gold coating and analyzed by a scanning electron microscope (JEOL JSM 5500). The average diameter of the fibers was determined by performing measurements on 60 fibers.

A capillary flow porometer (PMI, USA) was applied to evaluate the pore size distribution of nano- and microfibrous scaffolds. In a PMI porometer, a non-reacting gas flows through a dry sample and then through the same sample after it has been wet with isopropyl alcohol. The change in flow rate is evaluated as a function of pressure for both dry and wet processes [33]. Three samples from each material were used. For each sample, the pore size measurement was repeated three times.

Attenuated total reflectance-Fourier transform infrared spectroscopy (ATR-FTIR) was used to characterize the nano- and micro-fibrous scaffolds. FTIR spectra were recorded using the FTS Digilab 60 BioRad spectrophotometer (in the $400-4000 \mathrm{~cm}^{-1}$ range). All spectra were acquired through the accumulation of 64 scans at a resolution of $4 \mathrm{~cm}^{-1}$. One sample from each material was used in the study.

Water contact angles indicating the wetting ability of the nano- and micro-fibrous scaffolds were measured using drop shape analysis (DSA 10, KRUSS). A single droplet of doubly distilled water $(20 \mu \mathrm{L})$ was applied to the scaffold surface and contact angle measurements were taken at room temperature. Five measurements were done at different locations and the average value of the contact angle was obtained using standard deviation.

The tensile properties of the nanofibrous, microfibrous, and hybrid scaffolds were analyzed using a Zwick-Roell Z 2.5 testing machine at a cross-head speed of $10 \mathrm{~mm} / \mathrm{min}$. The rectangular samples were $10 \mathrm{~cm}$ long and $2 \mathrm{~cm}$ wide. At least three specimens were tested for each sample and the mean values of tensile strength were reported. The thickness of the scaffolds was determined using the thickness gage TILMET 73. The thickness test was performed on eight samples of each type of fibrous scaffolds. The values of the average thickness were determined.

The adhesion tests were done using a Zwick-Roell Z 2.5 testing machine at a cross-head speed of $10 \mathrm{~mm} / \mathrm{min}$. The rectangular samples were approximately $2.0 \times 2.0 \mathrm{~cm}$ and $0.5 \mathrm{~cm}$ high. Double-sided tape was placed on the surface of the compression plates and coated with a thin layer of superglue. The samples were then placed between the plates and the hybrid scaffold was compressed up to $-30 \mathrm{~N}$ and allowed to sit for $1 \mathrm{~min}$ to allow the glue to dry [21]. Then, the tensile test was performed until the two layers were separated. Three specimens for each test were considered. The maximum load and average adhesion strength were reported.

To determine the bioactivity of nano-/micro-fibrous scaffolds, the effect of the presence of n-HAp particles in the hybrid scaffold on apatite formation after immersion in simulated body fluid (SBF) was evaluated. In comparison, non-modified hybrid nano-/micro-fibrous scaffolds were also analyzed. Hybrid scaffolds were incubated for 7 days in $14 \mathrm{~mL}$ of $1.5 \times \mathrm{SBF}\left(\mathrm{pH} 7.4 ; 37^{\circ} \mathrm{C}\right)$. The $\mathrm{SBF}$ was prepared following Kokubo's protocol [34]. The surface morphology of the samples was examined by SEM.

All the data in this article has been presented as mean \pm standard deviation and has been analyzed using Student's $t$ test for the calculation of the significance level of the data. Differences were considered significant when $p \leq 0.05$.

\section{Results and discussion}

Interconnected nano- and micro-fibrous nonwovens were obtained using electrospinning and needle-punching processes. SEM images revealed a beadless, porous structure of the electrospun scaffolds (Fig. 1a, b). Some aggregated n-HAp particles in the case of nPCL/n-HAp nanofibers were observed. The fiber diameter histogram (Fig. 1c) revealed that most of the fibers were between 300 and $850 \mathrm{~nm}$ with the highest frequency occurring in the $500 \mathrm{~nm}$ range for modified $\mathrm{nPCL} / \mathrm{n}-\mathrm{HAp}$ nanofibers and in the $650 \mathrm{~nm}$ range for pure $\mathrm{nPCL}$ samples. It was found that the addition of n-HAp particles into the PCL solution can reduce the fiber diameter. It seems likely that the addition of n-HAp into the PCL solution can cause an increase in net charge density during electrospinning. An increase in net charge should increase the electrostatic force within the jet and result in higher stretching of the jet, hence the decrease in fiber diameter. On the other hand, n-HAp particles agglomerate easily, therefore, the measured fiber diameter for both types of nanofibrous scaffolds will be in a similar range $(300-1150 \mathrm{~nm})$. The SEM images of the micro-fibrous scaffolds obtained using the needle-punching process are shown in Fig. 1d and e. The mPCL and mPCL/ n-HAp fibers appeared randomly distributed without preferential orientation. The fiber's surface was affected by the mechanical intertwining of the fibers by needles. In addition, in the case of the mPCL/n-HAp sample, n-HAp agglomerates were seen on the fiber's surface. The fiber's diameter distribution is presented in Fig. 1f. The diameter of fibers varied from 20 to $80 \mu \mathrm{m}$ for pure mPCL 

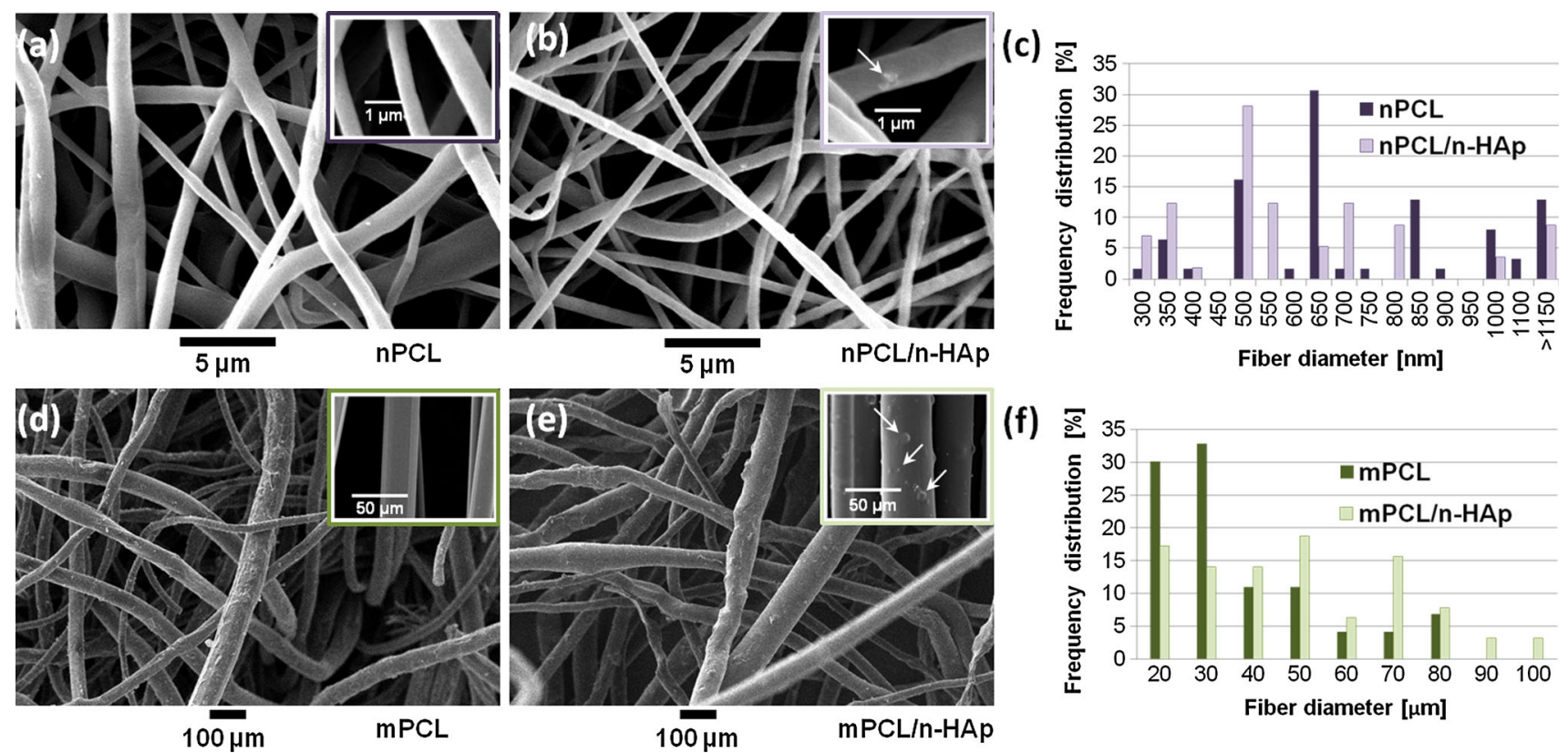

Fig. 1 SEM images and fiber diameter distributions for the fibrous scaffolds: a-c nano-fibrous nPCL and nPCL/n-HAp scaffold fabricated by electrospinning and $\mathbf{d}-\mathbf{f}$ micro-fibrous $\mathrm{mPCL}$ and mPCL/n-HAp scaffold fabricated using the needle-punching process

Fig. 2 Pore size distributions for fibrous scaffolds: a nanofibrous scaffold fabricated by electrospinning and $\mathbf{b}$ microfibrous scaffold fabricated using the needle-punching process
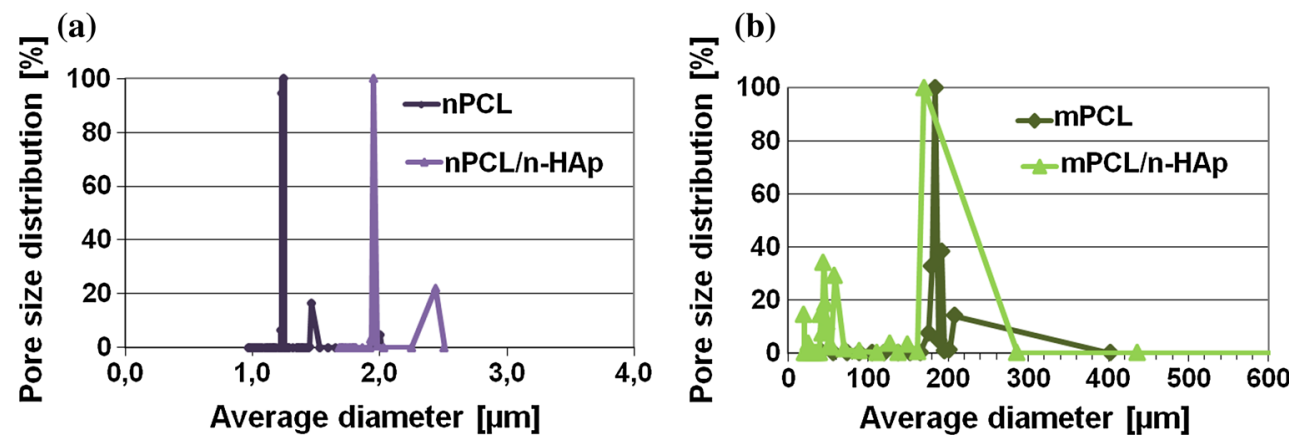

nonwoven and from 20 to $100 \mu \mathrm{m}$ for the modified mPCL/ n-HAp scaffold. The average diameter of the fibers was $37.6 \pm 17.7 \mu \mathrm{m}$ for pure $\mathrm{mPCL}$ and $49.9 \pm 21.7 \mu \mathrm{m}$ for composite $\mathrm{mPCL} / \mathrm{n}$-HAp fibers.

Figure 2 shows the pore size distribution of the electrospun nano-fibrous and needle-punched micro-fibrous scaffolds. The results revealed a very narrow distribution of pore size for nPCL and nPCL/n-HAp scaffolds centered at 1.2 and $2.0 \mu \mathrm{m}$, respectively (Fig. 2a). The results obtained confirmed a general view that the electrospinning technique allows one to obtain scaffolds with a highly porous network of interconnected pores [35]. However, the average pore size in electrospun nanofibrous scaffolds is insufficient for bone tissue engineering [17]. The relatively small pore size compared to the cellular diameter $(5-20 \mu \mathrm{m})$ could not allow cell migration within the scaffolds [19]. In the case of micro-fibrous scaffolds, pore size distribution was much wider
(Fig. 2b). The main pore fraction for n-HAp modified micro-fibrous samples was in the range of $160-280 \mu \mathrm{m}$, smaller pores in the range of $20-60 \mu \mathrm{m}$ were also present. In the case of pure mPCL samples, major pore fractions were in the range of 180-200 $\mu \mathrm{m}$ and 200-400 $\mu \mathrm{m}$.

Figure 3 shows FTIR spectra of nano- and micro-fibrous scaffolds as well as of pure n-HAp powder. Several characteristic bands of PCL were observed for both types of nanoand micro-fibrous samples at $1727 \mathrm{~cm}^{-1}$ ( $\mathrm{C}=\mathrm{O}$ stretching), $1293 \mathrm{~cm}^{-1}$ (C-O and C-C stretching), $1240 \mathrm{~cm}^{-1}$ (C-O-C asymmetric stretching), and $1175 \mathrm{~cm}^{-1}$ (C-O-C symmetric stretching) [36]. In the case of n-HAp modified scaffolds, some bands characteristic of n-HAp were identified. Although the main $v 3 \mathrm{PO}_{4}{ }^{3-}$ stretching mode at about $1033 \mathrm{~cm}^{-1}$ was overlapped by the PCL spectrum, the $v 4$ vibrational band was detected for nPCL/n-HAp and mPCL/n-HAp samples at 605 and $566 \mathrm{~cm}^{-1}$ [37]. The results confirmed a successful 
Fig. 3 FTIR spectra of fibrous scaffolds: a nano-fibrous scaffold fabricated by electrospinning (1) n-HAp, (2) nPCL, and (3) nPCL/n-HAp; b micro-fibrous scaffold fabricated using the needlepunching process (1) n-HAp, (2) $\mathrm{mPCL}$, and (3) mPCL/n-HAp
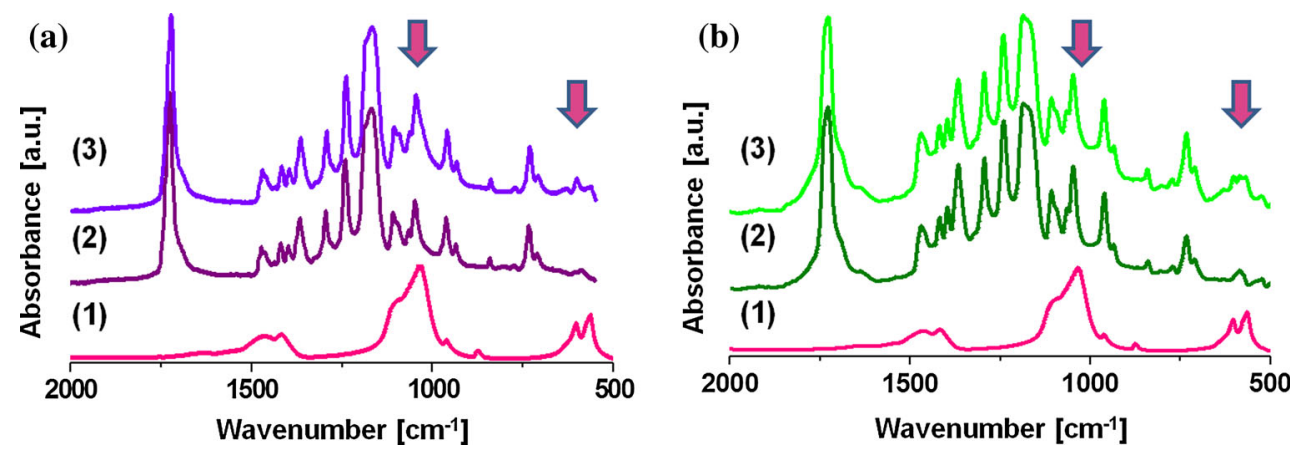

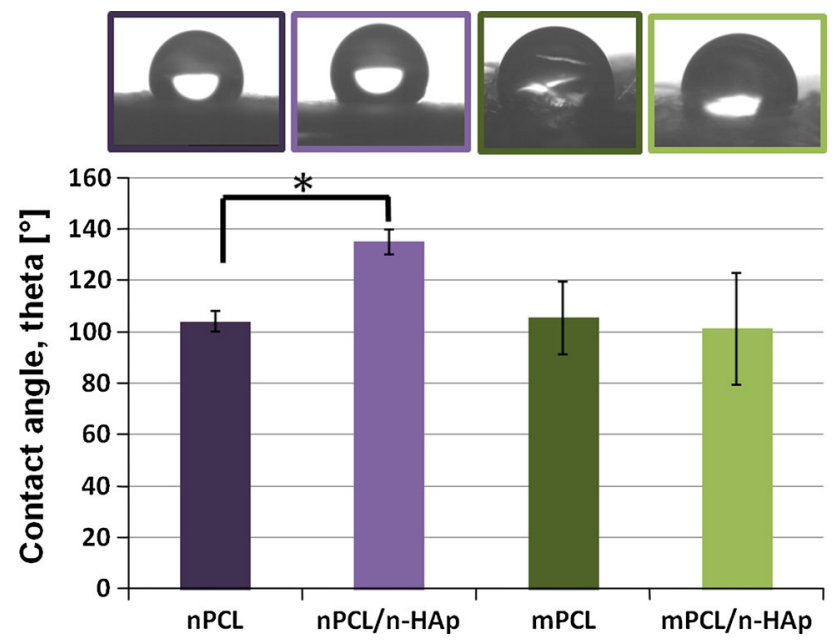

Fig. 4 The contact angle of nano- and micro-fibrous scaffolds. The data are expressed as the mean $\pm \mathrm{SD}(n=5)$. The asterisk indicates a statistically significant difference

incorporation of n-HAp particles both into the nano- and micro-fibrous scaffold.

The contact angle measurement was performed in order to understand the influence of n-HAp on micro- and nanofibrous scaffolds' surfaces wetting ability. Water contact angle values of the prepared scaffold are presented in Fig. 4a. All fibrous scaffolds revealed contact angles of over $100^{\circ}$, which means that water does not spread on the surface of these materials due to their hydrophobic properties. In addition, the incorporation of n-HAp nanoparticles within the nPCL nanofibrous scaffold (nPCL/n-HAp) increased the hydrophobicity of its surface and the highest value of the contact angle (about $135^{\circ}$ ) was observed using nPCL/n-HAp samples. The static contact angle measured is regulated by the surface chemistry and the surface roughness of the sample. The smoother the surface, the smaller the contact angle. The addition of n-HAp into the electrospun scaffolds increase the surface roughness resulting from the presence of extra crystallites on the fiber's surface and thus increases the contact angle. In the case of the nonwovens prepared with the traditional needle-punching technique, the addition of n-HAp has no effect on the change of the contact angle value.

Representative stress-strain curves and average tensile strengths of obtained nano-fibrous, micro-fibrous, and hybrid scaffolds are shown in Fig. 5. Nano- and microfibrous samples showed different tensile behavior (Fig. 5b, d). The stress and strain values of micro-fibrous scaffolds were lower compared to nano-fibrous scaffolds, indicating an inferior deformability and flexibility. The addition of n-HAp powder resulted in a decrease of mechanical properties of obtained nano- and micro-fibrous scaffolds, probably due to the agglomeration of n-HAp particles. Inorganic nanoparticles generally agglomerate easily and cannot be intermixed well. The addition of n-HAp particles creates weak links in the PCL matrix. These weak links become stress concentrators in a continuum matrix and thus reduce the tensile strength of the composite fibers. The tensile strength decrease ranges from $2.2 \mathrm{MPa}$ for an unmodified nano-fibrous scaffold to $1.3 \mathrm{MPa}$ for a composite nano-fibrous scaffold and, in the case of microfibrous scaffolds from $8.7 \mathrm{kPa}$, for an unmodified scaffold to $5.4 \mathrm{kPa}$ for composite scaffold (Fig. 5a, c). It should be noted that the higher porosity of micro-fibrous scaffolds is responsible for their lower tensile strength.

Hybrid scaffolds were fabricated using the same process parameters as those applied before for individual scaffold components. The typical morphology of the hybrid nano-/ micro-fibrous scaffolds obtained is presented in Fig. 6 . Homogenous deposition of the randomly orientated nanofibrous layer on the micro-fibrous nonwovens was observed in the case of both types of samples (n-HAp modified and non-modified). A micro-fibrous 3D porous structure served as a support for the nanofibrous mesh. The cross section revealed that nanofibers formed a layer with the thickness of about $115 \mu \mathrm{m}$.

In Fig. 7, the pore size distribution for both hybrid materials is presented. The unmodified hybrid H-PCL scaffolds show a bimodal distribution of pore sizes, centered around $3.0 \mu \mathrm{m}$ and in the range of $20-58 \mu \mathrm{m}$. In the case of modified hybrid H-PCL/n-HAp, the main fraction of pores is in the range of $26-32 \mu \mathrm{m}$. Capillary flow 
Fig. 5 Tensile strength and typical stress/strain curves of (a, b) nanofibrous, (c,

f) nano-/micro-hybrid scaffolds. The data are expressed as the mean $\pm \mathrm{SD}(n=3)$. The asterisk indicates a statistically significant difference d) microfibrous, and (e,
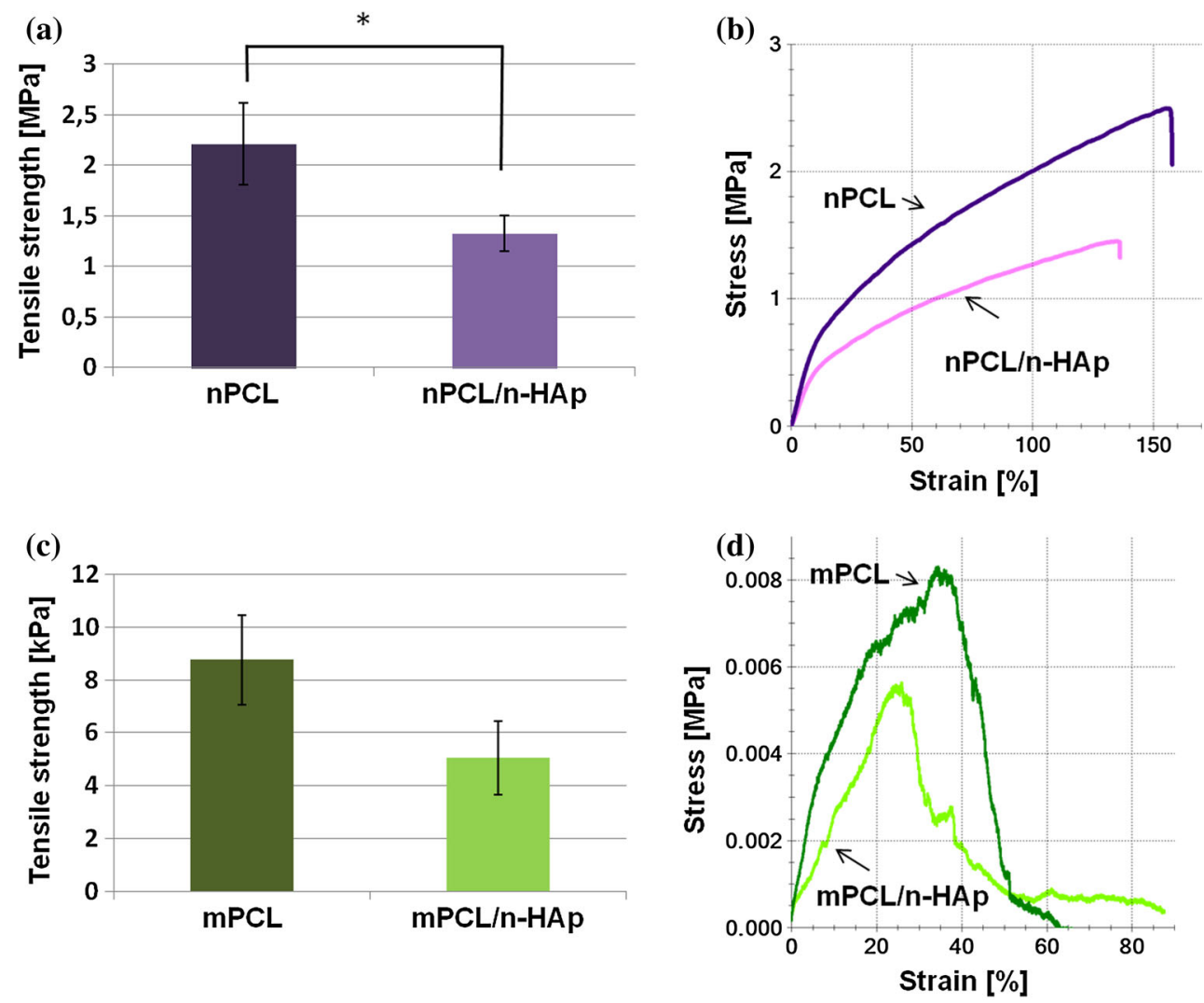

(e)
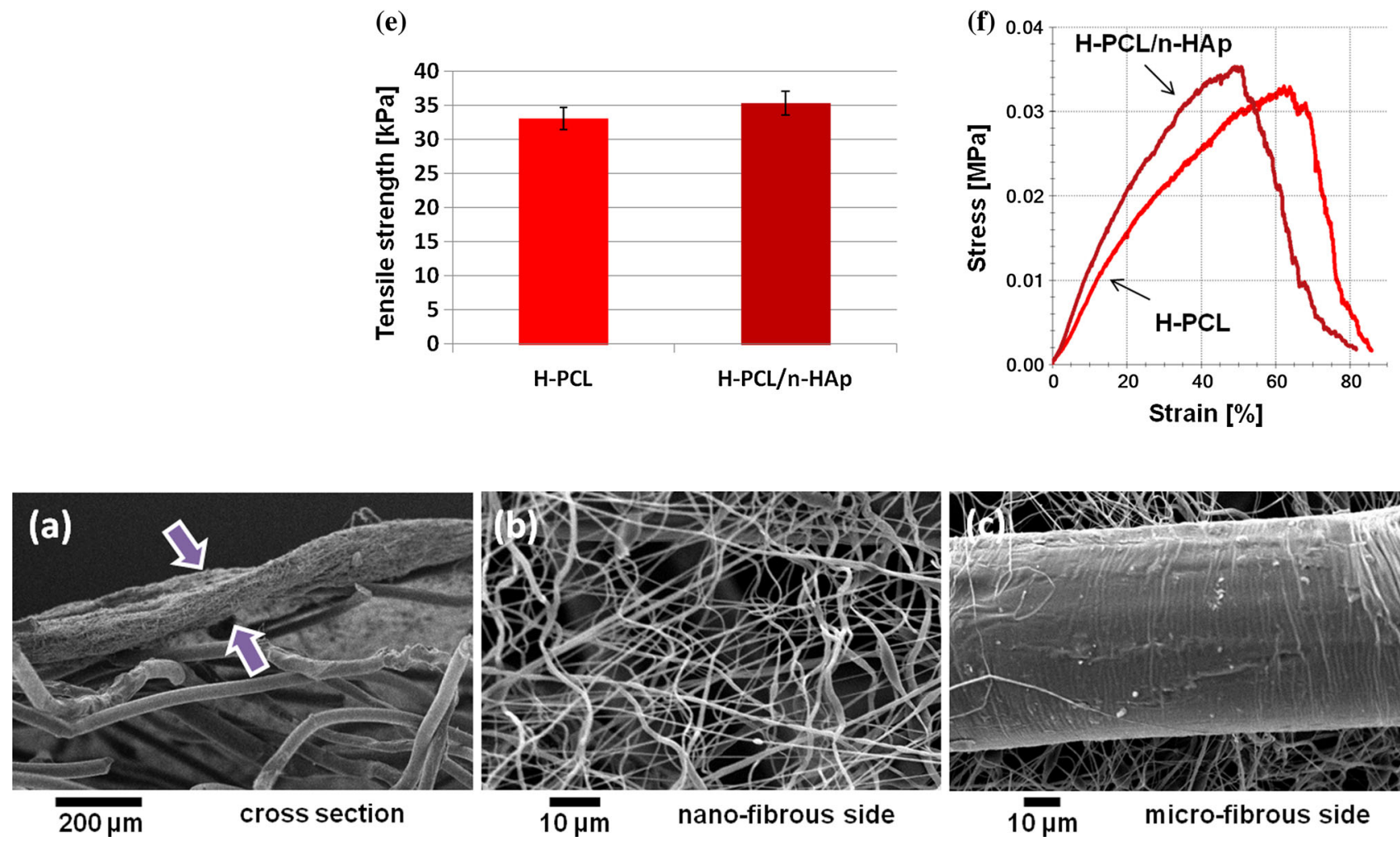

$10 \mu \mathrm{m}$ nano-fibrous side

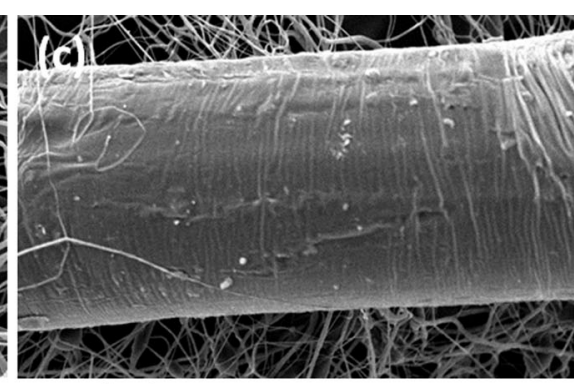

$10 \mu \mathrm{m}$ micro-fibrous side

Fig. 6 Microstructure of H-PCL hybrid scaffold a cross section, b nano-fibrous side of scaffold, and $\mathbf{c}$ micro-fibrous side of scaffold 


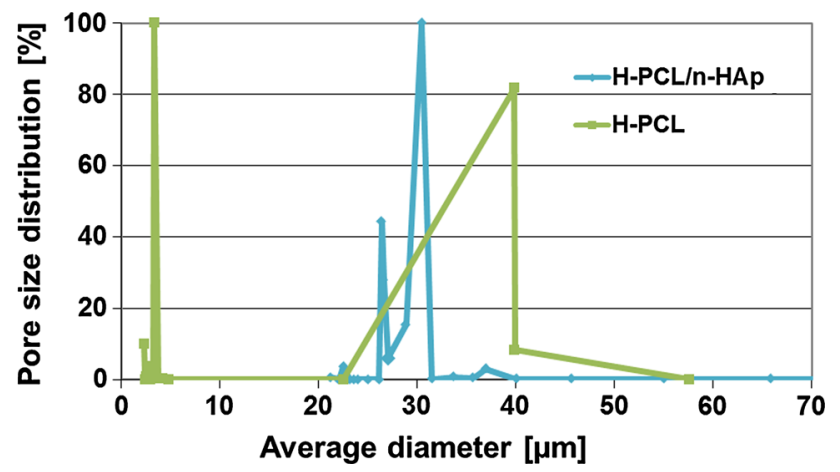

Fig. 7 Pore size distribution for hybrid nano-/micro-fibrous scaffold

porometry assumes a cylindrical pore or capillary of varying diameter through the thickness of the scaffold and measures only its smallest diameter (throat diameter) [38]. The results indicate that, in hybrid bilayered scaffolds composed of nano- and micro-fibers, it is possible to obtain three types of pore size ranges: (1) pores larger than $200 \mu \mathrm{m}$ (pores in which cells could grow), (2) smaller pores dedicated to the diffusion of nutrients or/and metabolites of bone-forming cells $(20-40 \mu \mathrm{m})$, and (3) pores enabling better neovascularization and cell attachment $(2-5 \mu \mathrm{m})$.

The mechanical properties of the microfibrous scaffolds were improved remarkably by introducing a nanofibrous layer. The hybrid scaffolds had much higher tensile strength than mPCL and mPCL/n-HAp scaffolds (Fig. 5e, f).

Figure 8a and $\mathrm{b}$ shows a representative curve of the adhesion tests. The first linear part of the curve is the recovery from the $-30 \mathrm{~N}$ compression step. At around $0 \mathrm{~N}$, the slope of the curve changed, corresponding to the point where the scaffold was not compressed any more, i.e., the start of the adhesion test. The load increased up to a peak and then gradually decreased. At this stage, one of the layers was completely separated from an adjacent layer. Adhesion strength values and standard deviation associated with H-PCL and H-PCL/n-HAp samples are shown in Fig. 8c. The adhesion load was around $2 \mathrm{~N}$ for both types of hybrid scaffolds. Non-modified H-PCL scaffolds had an adhesion strength of $2.8 \pm 0.8 \mathrm{kPa}$ and modified H-PCL/ $\mathrm{n}$-HAp scaffolds had an adhesion strength of $3.7 \pm 0.5 \mathrm{kPa}$. There were no significant differences among the adhesion strength values of H-PCL and H-PCL/n-HAp samples.

The bone-bonding ability of hybrid materials was evaluated by examining the ability of apatite to form on its surface in a SBF with ion concentrations nearly equal to those of human blood plasma. The macroscopic images of hybrid bilayer scaffolds after immersion in SBF for 7 days are shown in Fig. 9. Obviously, no apatite-like materials were precipitated within incubation of a pure (not modified) H-PCL hybrid scaffold (Fig. 9a, b). However, with the introduction of n-HAp nanoparticles into the hybrid H-PCL/n-HAp scaffold, the formation of calcium phosphate occurred and an apatite-like mineral layer completely covered the surface of the sample (Fig. 9c, d). The surface of apatite layer deposited by immersion in SBF was formed by globular structures. Preliminary results showed that the presence of n-HAp particles within the nano- and microfibrous hybrid scaffold provokes the nucleation of calcium phosphate in SBF.

In this study, bioactive hybrid scaffolds were fabricated through direct spinning of nanofibers on micro-fibrous nonwovens. Both scaffold layers were modified with $\mathrm{n}$-HAp in order to ensure the bioactive character of the final hybrid scaffold. The presence of n-HAp was confirmed by FTIR and SEM studies. The materials usually proposed for bone tissue engineering made of ECM-mimicking nanofibrous electrospun mats cannot be used as 3D scaffolds due to their very small pore size. It is well known that pore size distribution, porosity, and pore interconnectivity are crucial parameters for tissue engineering scaffolds as they provide (a)

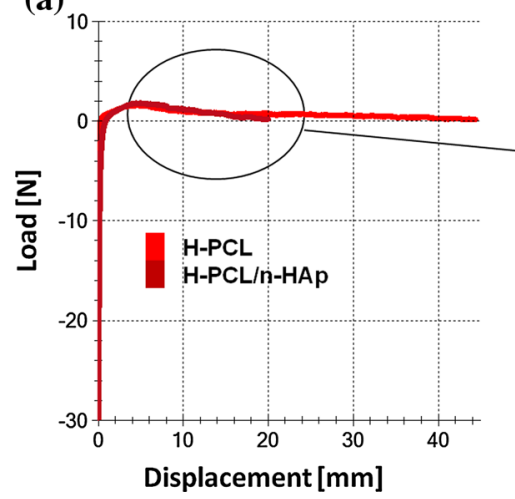

(b)

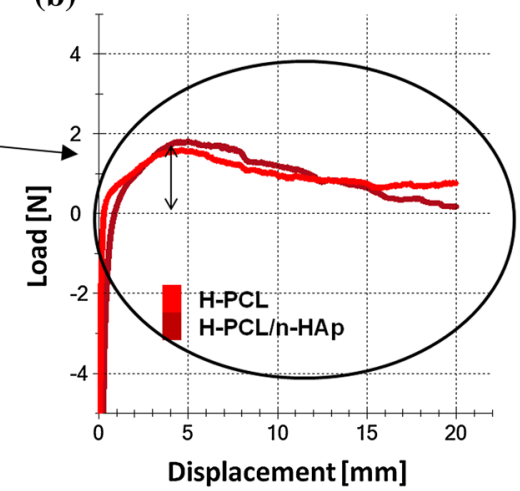

(c)

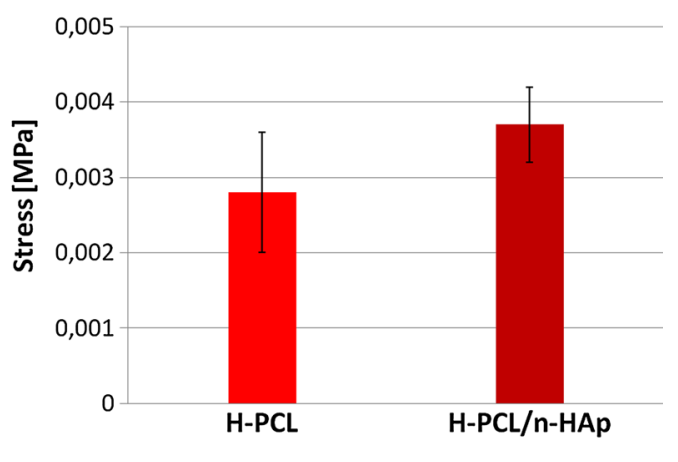

Fig. 8 Representative curves of the adhesion tests of the H-PCL and H-PCL/n-HAp hybrid scaffolds (a, b), adhesion strength of hybrid scaffolds (c). There were no significant differences among the H-PCL and H-PCL/n-HAp samples 
Fig. 9 Microstructure of H-PCL $(\mathbf{a}, \mathbf{b})$ and H-PCL/nHAp (c, d) scaffolds after 7 days of immersion in SBF
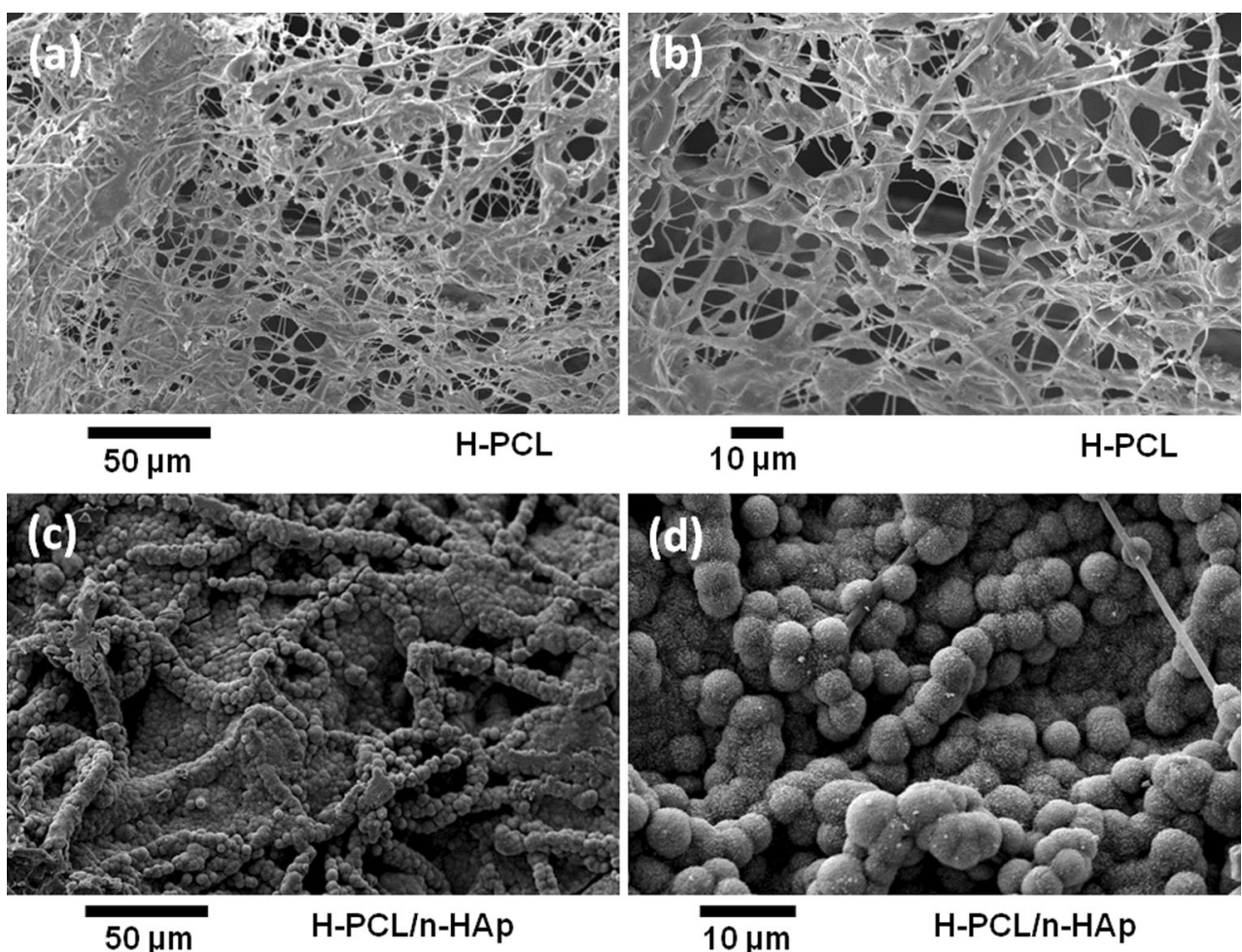

the optimal spatial and nutritional conditions for the cells and determine the successful integration of the natural bone tissue and the material, as well as enabling neovascularization and cell attachment. By combining nano-fibers with micro-fibers, a new scaffold material with a 3D structure and different pore size ranges was obtained. Such bilayer material can be used to separate and allow for the independent proliferation of two distinct tissue types: soft tissue on one side and bone tissue on the other side. The bioactive character of these hybrid scaffolds was confirmed by an SBF mineralization study. After only 7 days, the hybrid scaffold surface was already completely covered by apatite deposits, proving the biocompatibility of these materials.

\section{Conclusions}

The main objective of this study was to obtain new hybrid nano-/micro-fibrous materials which could be prospectively applied as three-dimensional porous scaffolds for bone tissue engineering purposes. In this study, it was determined that the combined use of two techniques, namely electrospinning and needle-punching processes, could be beneficial for the fabrication of 3D bioactive scaffolds with a desired pore size and a final nano-/microfibrous structure. Such scaffolds can be successfully used in the body to separate soft tissue from bone tissue in order to allow for new bone growth.
Acknowledgements This study was supported by the Polish Ministry of Science and Higher Education (Project Iuventus Plus II No. IP2011044671) and by the Polish National Science Center (Project No. N507550938).

Open Access This article is distributed under the terms of the Creative Commons Attribution License which permits any use, distribution, and reproduction in any medium, provided the original author(s) and the source are credited.

\section{References}

1. Liu C, Xia Z, Czernuszka T (2007) Design and development of three-dimensional scaffolds for tissue engineering. Trans IChemE A 85(A7):1051-1064

2. Tuzlakoglu K, Reis RL (2009) Biodegradable polymeric fiber structures in tissue engineering. Tissue Eng B 15(1):17-27

3. Tuzlakoglu K, Santos MI, Neves N, Reis RL (2011) Design of nano- and microfiber combined scaffold by electrospinning of collagen onto starch-based fiber meshes: a man-made equivalent of natural extracellular matrix. Tissue Eng A 17(3-4):463-473

4. Jang J-H, Castano O, Kim H-W (2009) Electrospun materials as potential platforms for bone tissue engineering. Adv Drug Deliv Rev 61:1065-1083

5. Ngiam M, Liao S, Patil AJ, Cheng Z, Chan CK, Ramakrishna S (2009) The fabrication of nano-hydroxyapatite on PLGA and PLGA/collagen nanofibrous composite scaffolds and their effects in osteoblastic behavior for bone tissue engineering. Bone 45:4-16

6. Rajzer I, Menaszek E, Kwiatkowski R, Chrzanowski W (2014) Bioactive nanocomposite PLDL/nano-hydroxyapatite electrospun membranes for bone tissue engineering. J Mater Sci Mater Med 25(5):1239-1247. doi:10.1007/s10856-014-5149-9 
7. Prabhakaran MP, Ghasemi-Mobarakeh L, Ramakrishna S (2011) Electrospun composite nanofibers for tissue regeneration. J Nanosci Nanotechnol 11(4):3039-3057

8. Stodolak-Zych E, Szumera M, Blazewicz M (2013) Osteoconductive nanocomposite materials for bone regeneration. Mater Sci Forum 730-732:38-43

9. Fabbri P, Bondioli F, Messori M, Bartoli C, Dinucci D, Chiellini F (2010) Porous scaffolds of polycaprolactone reinforced with in situ generated hydroxyapatite for bone tissue engineering. J Mater Sci Mater Med 21:343-351

10. Stodolak-Zych E, Fraczek-Szczypta A, Wiechec A, Blazewicz M (2012) Nanocomposite polymer scaffolds for bone tissue regeneration. Acta Phys Pol A 121(2):518-521

11. Lu Z, Roohani-Esfahani S-I, Kwok PCL, Zreiqat H (2011) Osteoblasts on rod shaped hydroxyapatite nanoparticles incorporated PCL film provide an optimal osteogenic niche for stem cell differentiation. Tissue Eng A 17(11-12):1651-1661

12. Rajzer I, Menaszek E (2012) Cell differentiation on electrospun poly(epsilon-caprolactone) membranes modified with hydroxyapatite. J Tissue Eng Regen Med 6(Supplement 1):194

13. Bianco A, Federico ED, Moscatelli I, Camaioni A, Armentano I, Campagnolo L, Dottori M, Kenny JM, Siracusa G, Gusmano G (2009) Electrospun poly(E-caprolactone)/Ca-deficient hydroxyapatite nanohybrids: microstructure, mechanical properties and cell response by murine embryonic stem cells. Mater Sci Eng C 29:2063-2071

14. Sanzana ES, Navarro M, Ginebra MP, Planell JA, Ojeda AC, Montecinos HA (2013) Role of porosity and pore architecture in the in vivo bone regeneration capacity of biodegradable glass scaffolds. J Biomed Mater Res A 102:1767-1773. doi:10.1002/ jbm.a.34845

15. Pham QP, Sharma U, Mikos AG (2006) Electrospun poly( $\varepsilon-$ caprolactone) microfiber and multilayer nanofiber/microfiber scaffolds: characterization of scaffold and measurement of cellular infiltration. Biomacromolecules 7:2796-2805

16. Lee JB, Jeong SI, Bae MS, Yang DH, Heo DN, Kim CH, Eben Alsberg E, Kwon IK (2011) Highly porous electrospun nanofibers enhanced by ultrasonication for improved cellular infiltration. Tissue Eng A 17(21-22):2695-2702

17. Tuzlakoglu K, Bolgen N, Salgado AJ, Gomes ME, Piskin E, Reis RL (2005) Nano- and micro-fiber combined scaffolds: a new architecture for bone tissue engineering. J Mater Sci Mater Med 16:1099-1104

18. Shalumon KT, Chennazhi KP, Tamura H, Kawahara K, Nair SV, Jayakumar R (2012) Fabrication of three-dimensional nano, micro and micro/nano scaffolds of porous poly(lactic acid) by electrospinning and comparison of cell infiltration by Z-stacking/ three-dimensional projection technique. IET Nanobiotechnol 6(1): $16-25$

19. Kim SJ, Jang DH, Park WH, Min B-M (2010) Fabrication and characterization of 3-dimensional PLGA nanofiber/microfiber composite scaffolds. Polymer 51(6):1320-1327

20. Srouji S, Kizhner T, Suss-Tobi E, Livne E, Zussman E (2008) 3-D Nanofibrous electrospun multilayered construct is an alternative ECM mimicking scaffold. J Mater Sci Mater Med 19:1249-1255

21. Vaquette C, Cooper-White J (2013) A simple method for fabricating 3-D multilayered composite scaffolds. Acta Biomater 9:4599-4608

22. Vaquette C, Cooper-White J (2012) The use of an electrostatic lens to enhance the efficiency of the electrospinning process. Cell Tissue Res 347:815-826
23. Chung S, Ingle NP, Montero GA, Kim SH, King MW (2010) Bioresorbable elastomeric vascular tissue engineering scaffolds via melt spinning and electrospinning. Acta Biomater 6:1958-1967

24. Santos MI, Tuzlakoglu K, Fuchs S, Gomes ME, Peters K, Unger RE, Piskin E, Reis RL, Kirkpatrick CJ (2008) Endothelial cell colonization and angiogenic potential of combined nano- and micro-fibrous scaffolds for bone tissue engineering. Biomaterials 29:4306-4313

25. Rajzer I, Grzybowska-Pietras J, Janicki J (2011) Fabrication of bioactive carbon nonwovens for bone tissue regeneration. Fibres Text East Eur 84(1):66-72

26. Kasoju N, Bhonde RR, Bora U (2009) Fabrication of a novel micro-nano fibrous nonwoven scaffold with Antheraea assama silk fibroin for use in tissue engineering. Mater Lett 63:2466-2469

27. Rajzer I, Rom M, Błażewicz M (2010) Production and properties of modified carbon fibers for medical applications. Fiber Polym 11(4):615-624

28. Pielichowska K, Blazewicz S (2010) Bioactive polymer/ hydroxyapatite (nano)composites for bone tissue regeneration. Adv Polym Sci 232(1):97-207

29. Bye FJ, Bissoli J, Black L, Bullock AJ et al (2013) Development of bilayer and trilayer nanofibrous/microfibrous scaffolds for regenerative medicine. Biomater Sci 1:942-951

30. Ślósarczyk A, Paszkiewicz Z, Zima A (2010) The effect of phosphate source on the sintering of carbonate substituted hydroxyapatite. Ceram Int 36(2):577-582

31. Rajzer I, Fabia J, Graczyk T, Piekarczyk W (2013) Evaluation of PCL and PCL/n-HAp fibres processed by melt spinning. Eng Biomater 118:2-4

32. Rajzer I, Rom M, Fabia J, Sarna E, Janicki J (2010) Fabrication and characterization of bioactive PLA fibers for bone tissue engineering. In: 23rd European conference on biomaterials, Tampere, Finland, p. 448. ISBN 978-1-61782-086-1

33. Li D, Frey MW, Joo YL (2006) Characterization of nanofibrous membranes with capillary flow porometry. J Membr Sci 286:104-114

34. Kokubo T, Takadama H (2006) How useful is SBF in predicting in vivo bone bioactivity? Biomaterials 27(15):2907-2915

35. Wang N, Burugapalli K, Song W, Halls J, Moussy F, Zheng Y, Ma Y, Wu Z, Li K (2013) Tailored fibro-porous structure of electrospun polyurethane membranes, their size-dependent properties and trans-membrane glucose diffusion. J Membr Sci 427:207-2017

36. Gautam S, Dinda AK, Mishra NC (2013) Fabrication and characterization of PCL/gelatin composite nanofibrous scaffold for tissue engineering applications by electrospinning method. Mater Sci Eng C 33:1228-1235

37. Rajzer I, Kwiatkowski R, Piekarczyk W, Biniaś W, Janicki J (2012) Carbon nanofibers produced from electrospun PAN/HAp precursors as scaffolds for bone tissue engineering. Mater Sci Eng C 32(8):2562-2569

38. Szentivanyi A, Chakradeo T, Zernetsch H, Glasmacher B (2011) Electrospun cellular microenvironments: understanding controlled release and scaffold structure. Adv Drug Deliv Rev 63:209-220 